\title{
A CASE OF CUTANEOUS LEISHMANIASIS TREATED WITH HYPERBARIC OXYGEN THERAPY
}

\author{
$\frac{\text { Romuald Olszański }{ }^{1)}}{\text { A }^{3}}, \quad$ Piotr Siermontowski ${ }^{1)}$, Dariusz Juszczak ${ }^{2)}$, Zbigniew Dąbrowiecki ${ }^{1)}$, \\ Agnieszka Pedrycz ${ }^{3}$ \\ Maritime \& Hyperbaric Medicine Department, Military Institute of Medicine, Gdynia, Poland \\ 2) 7 Naval Hospital, Gdańsk, Poland \\ 3) Department of Histology and Embryology, Medical University in Lublin, Poland
}

\begin{abstract}
Cutaneous leishmaniasis in Poland is an imported disease mainly occurring in tourists who travelled to tropical countries. Cutaneous symptoms occur as late as between ten and twenty days following the return from the tropics. Lesions connected with cutaneous leishmaniasis were most commonly diagnosed by Polish doctors as furuncle, ecthyma or ulceration and ineffectively treated for several weeks with antibiotics.

The paper presents the case of leishmaniasis in a 30-year-old male with an ulceration of the left shank, ineffectively treated with antibiotics over a period of four months. The ulceration was healed completely only after leishmaniasis was diagnosed and following the application of a treatment based on antimony derivatives, followed by hyperbaric oxygenation performed in a hyperbaric chamber.

Key words: leishmaniasis, antimony, hyperbaric oxygenation.
\end{abstract}

ARTICLE INFO

PolHypRes 2016 Vol. 57 Issue 4 pp. 39 - 46

ISSN: $1734-7009$ eISSN: 2084-0535

DOI: $10.1515 / \mathrm{phr}-2016-0024$

Pages: 8 , figures: 3 , tables: 0

page www of the periodical: www.phr.net.pl

Publisher

Polish Hyperbaric Medicine and Technology Society
Casuistic article (case study)

Submission date: $12.04 .2015 \mathrm{r}$

Acceptance for print: 09.09.2016r 


\section{INTRODUCTION}

Leishmaniasis; synon: eastern ulcer, Cutaneous leishmaniasis, Aleppo button, Baghdad boi, Delhi ulcer, Leishmania major, Leishmania tropica, Oriental sore Leishmaniasis is induced by Leishmania protozoa. Potential carriers of the disease consist of over 100 mammalian species - domestic animals (mainly dogs, rarer cats and horses), wild animals (foxes, jackals, sloths, rats, mice), as well as amphibians, reptiles, birds. Leishmania protozoa are transferred onto a humans by blood-feeding females of the genus Phleotomus (in Africa, Asia and Europe) as well as Lutzomyia and Psychodopygus (in Latin and South America). Several weeks from an incident, chronic ulceration appears in the bite site which later transforms into a disfiguring scar. Skin lesions occur mainly on uncovered body parts, i.e. on the face, neck and limbs [1,2,3].

Cutaneous leishmaniasis occurs in the Middle East, north Africa, Latin and South America, as well as in Mediterranean countries (mainly the Greek islands, Cyprus, Sicily). Is has not been noted in Australia. Although the disease appears in 88 countries, $90 \%$ of cutaneous leishmaniasis mainly concerns Afghanistan, Iran, Saudi Arabia, Syria, Brazil and Peru. Approximately 12 million people are affected by this disease, while the number of new instances of cutaneous leishmaniasis on a yearly basis amounts to ca. 1.5 million. About 350 million people currently live in areas at risk of leishmaniasis.

There are between ten and twenty species of pathogenic Leishmania species responsible for the cutaneous leishmaniasis that affects humans: L. tropica, L. major, L. minor, L. aethiopica, L. mexicana, L. amazonensis, L. venezuelensis, L. guyanensis, L. peruviana. Leishmania is transmitted by sand flies: Phlebotomus (Africa, Middle East) and Lutzomyia (Latin and South America). Sand flies are small insects with the body length of $4 \mathrm{~mm}$.

During the day they remain in shaded places and become active at dusk and during the night. By biting a person who is already inflicted with leishmaniasis, a fly becomes infected, through the blood, with the amastigote form, which transforms in its body into the promastigote form. The cycle lasts up to 15 days. Next, the promastigote moves to the glandular part of the insect's mouthparts and as a result of a bite is introduced into the skin of a healthy person.

In humans, the promastigote form transforms into the amastigote form which is found inside the cells of the reticuloendothelial system of the liver, spleen, bone marrow, lymph nodes, lungs and skin $[1,2,3]$.

\section{Clinical FORMS OF CUTANEOUS}

\section{LEISHMANIASIS}

1. Dry or urban sore induced by Leishmania tropica. The disease is commonly chronic in character and lasts from 6 up to 18 months. An erythematous papule appears in the bite area which gradually enhances after several weeks or months and transforms into a hard dark-red nodule with crater-like edges, whereas in the central part of the nodule a shallow crusted ulceration appears. Next, the ulceration heals leaving a concave scar. An occurrence of small satellite nodules at the edges of ulcerations is common. After the healing process, a disfiguring concave scar remains. Lymphadenopathy does not occur. Dogs are a common carrier of this variant disease.

2. Wet or rural sore induced by Leishmania major. It is characterised by a faster course with large ulceration, often accompanied by secondary bacterial infection. Healing occurs as late as upon the lapse of 24 months, leaving a deep scar. It is often accompanied with regional lymphadenopathy. The carriers of this variant of the disease are rodents.

3. Disseminated form - subcutaneous nodules occurring along the lymphatic ducts.

4. Furuncle-like form commonly induced by Leishmania major. Treatment of several months leaves a concave scar.

5. Other forms: pathological eruptions: sarcoidlike, impetigo-like, wart-like, lupoid-like.

Cutaneous leishmaniasis should be differentiated from furuncle or ecthyma, impetigo, mycosis, psorasis, epithelioma, lupus erythematosus, tropical ulcer, tertiary syphilis or even leprosy [4].

In the initial phase of cutaneous leishmaniasis with light eruptions, cryotherapy proves very efficient and safe $[5,6]$.

\section{THERAPY}

- first-line therapy: treatment with the derivatives of pentavalen antimony (Pentostam, Glucantime) $\quad 20 \quad \mathrm{mg} / \mathrm{kg}$ administered intravenously or intra-muscularly over a period of 21 days,

- second-line therapy: Katoconazole $600 \mathrm{mg}$ administered orally once a day over a period of 28 days or Itraconazole $200 \mathrm{mg}$ administered orally twice a day over a period of 28 days,

- locally: cryotherapy, surgical intervention $[5,6]$.

Every year over 1 million Poles travel to tropical countries where cutaneous leishmaniasis occurs (Egypt 600 thousand, Tunisia 400 thousand). The symptoms appear as late as about two weeks after the return and commonly neither the doctor nor the patient note the connection between the skin lesions and the stay in the tropics.

For this reason, cutaneous leishmaniasis is commonly diagnosed by Polish doctors as furuncle, ecthyma or ulceration and ineffectively treated for several weeks with antibiotics. However, the problem of a wrong diagnosis, and, in consequence, of a wrong treatment of cutaneous leishmaniasis occurs also in other European countries and in the USA, even in China.

As statistics show, the wrong treatment was applied there in relation to nearly each case of leishmaniasis due to a diagnosis being delayed by at least several weeks $[7,8,9,10,11]$. In the Middle East the incidence of leishmaniasis is very rare. The first case of cutaneous leishmaniasis was described in Thailand [12]. There is no protective vaccination against leishmaniasis and the best prophylaxis consists in using repellents and avoiding insect bites [13]. Leishmanisis diagnostics is also performed with the use of dermoscopy [14]. 


\section{CASe DesCRIPTION}

A male, 30 years of age, stayed in the Middle East. Approximately 6 weeks after his return, a painless lump appeared in the prolateral part of the left lower leg, followed by a furuncle which transformed into a nonhealing ulceration. Despite treatment commenced by several dermatologists, the ulceration progressed (fig.1).

Microscopic examination of a skin section confirmed the presence of developmental amastigote form. The result was a highly positive antibody titre towards Leishmania spp. and detection of parasitic genetic material with the PCR method performed on sections from the area of ulceration.

Treatment with derivatives of a pentavalen antimony was initiated (Glucantime i.m.) resulting in gradual improvement. Upon treatment completion, the results of microscopic and PCR examinations on skin sections were negative (fig. 2). Next, hyperbaric oxygenation was prescribed resulting in significant improvement (fig. 3)

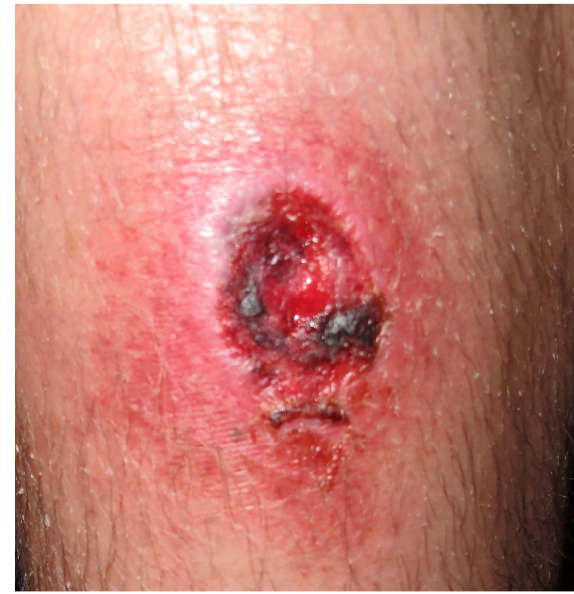

Fig. 1. Cutaneous leishmaniasis - before diagnosis

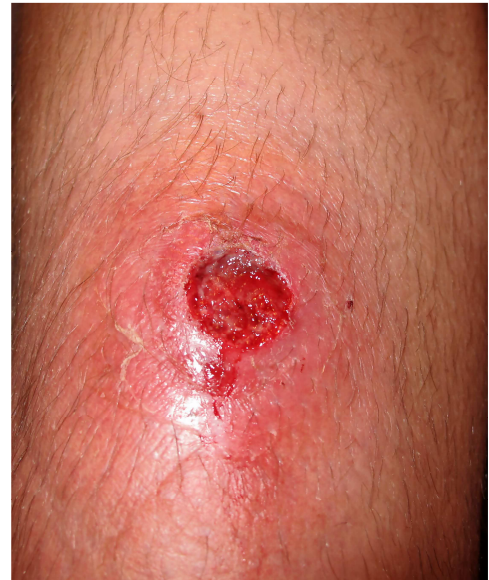

Fig. 2. Cutaneous leishmaniasis - following treatment with antimony derivatives.

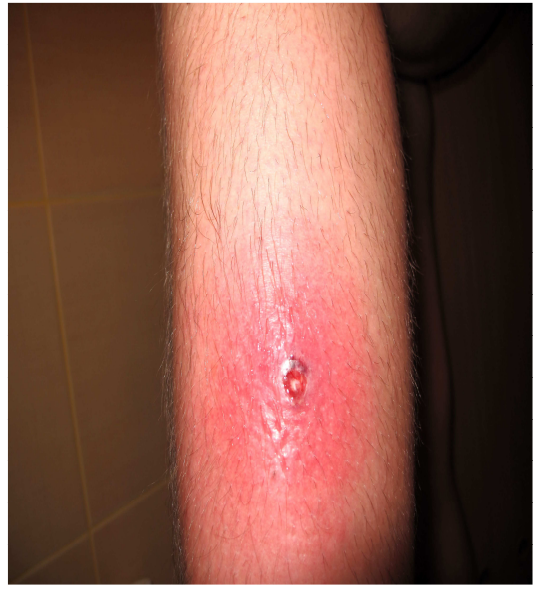

Fig. 3 Cutaneous leishmaniasis following hyperbaric oxygen therapy.

\title{
BIBLIOGRAPHY
}

1. Vasievich MP, Villarreal JD, Tomecki KJ.Got the Travel Bug? A Review of Common Infections, Infestations, Bites, and Stings Among Returning Travelers. Am J Clin Dermatol. 2016 Oct;17(5):451-462;

2. Ergen EN, King AH, Tuli M.Cutaneous leishmaniasis: an emerging infectious disease in travelers. Cutis. 2015 Oct;96(4):E22-6;

3. Olszański R. Health problems in the tropics WIM Warsaw 2014;

4. Saab J, Fedda F, Khattab R, Yahya L, Loya A, Satti M, Kibbi AG, Houreih MA, Raslan W, El-Sabban M, Khalifeh I. Cutaneous leishmaniasis mimicking inflammatory and neoplastic processes: a clinical, histopathological and molecular study of 57 cases. J Cutan Pathol. 2012;39(2):251-62

5. Mohammadzadeh M, Behnaz F, Golshan Z. Efficacy of glucantime for treatment of cutaneous leishmaniasis in Central Iran. J.Infect Public Health. 2013; 6(2):120-4

6. Negera E, Gadisa E, Hussein J, Engers H, Kuru T, Gedamu L, Aseffa A. Treatment response of cutaneous leishmaniasis due to Leishmania aethiopica to cryotherapy and generic sodium stibogluconate from patients in Silti, Ethiopia. Trans R Soc Trop Med Hyg. 2012;106(8):496-503;

7. Bart A, van Thiel P, de Vries H, Hodiamont C, Van Gool T. Imported leishmaniasis in the Netherlands from 2005 to 2012: epidemiology, diagnostic techniques and sequence-based species typing from 195 patients. Euro Surveill. 2013 Jul 25;18(30):1-8;

8. Stebut E, Schleicher U, Bogdan C. Cutaneous leishmaniasis as travelers' disease. Clinical presentation, diagnostics and therapy]. Hautarzt 2012; 63(3):233-46;

9. Poeppl W, Oeser C, Grabmeier-Pfistershammer K, Walochnik J, Burgmann H.Clinical findings and management of imported cutaneous leishmaniasis: report of 14 cases from Austria. Travel Med Infect Dis. 2013; 11, 90-94;

10. Kelly P, Baudry T, Peyron F. Imported cutaneous leishmaniasis in a short-term traveler returning from Central Mali - The role of PCR. Travel Med Infect Dis. 2012;10(2):97-100;

11. Zhang M, Liu F, Liu H, Hu W, Sang H. Imported cutaneous leishmaniasis caused by Leishmania major in a Chinese laborer who worked in Saudi Arabia. An Bras Dermatol. 2016 ;91(3):365-7;

12. Kattipathanapong $P$, Akaraphanth $R$, Krudsood S, Riganti M, Viriyavejakul P. The first reported case of autochthonous cutaneous leishmaniasis in Thailand. Southeast Asian J Trop Med Public Health. 2012;43(1):17-20;

13. Okwor I, Mou Z, Liu D, Uzonna J.Protective immunity and vaccination against cutaneous leishmaniasis. Front Immunol. 2012;3:128;

14. Cembrero-Saralegui H, Martínez Pérez M, Imbernón-Moya A. [Dermoscopy of acute cutaneous leishmaniasis]. Med Clin (Barc). 2016 Sep 19. pii: S0025-7753(16)30363-3.

\author{
prof. dr hab. med. Romulad Olszańsk \\ Zakład Medycyny Morskiej i Hiperbarycznej \\ Wojskowy Instytut Medyczny \\ ul. Grudzińskiego 4 81-103 Gdynia 3 \\ skr. poczt. 18 \\ e-mail: romuald.olszanski@wp.pl
}

